\title{
Characteristics of pain and disability among patients with chronic neck pain attended at centre for the rehabilitation of the paralysed (CRP)
}

\begin{abstract}
Objectives: The objectives of the study were to find out the demography of the participants, to find out the medical information, characteristics of pain and disability among patients with chronic neck pain.
\end{abstract}

Methods: The study design was prospective cross sectional survey in which pain was measured by numerical pain rating (NPR) scale and disability by neck disability index (NDI).

Results: The mean age of participants was 43.93( \pm 9.75$)$ years. Among the 60 participants, $40(67 \%)$ were female and $20(33 \%)$ participants were male. The severity of neck pain as per $10 \mathrm{~cm}$ NPR scale showed that 22(37\%) participants were at scale level $3 \mathrm{~cm}, 13(22 \%)$ were at scale level $4 \mathrm{~cm}, 18(30 \%)$ were at scale level $5 \mathrm{~cm}, 3(5 \%)$ were at $6 \mathrm{~cm}, 2(3 \%)$ were at $7 \mathrm{~cm}$ and $2(3 \%)$ were at $8 \mathrm{~cm}$ scale level. In the disability characteristics among 60 participants, no participants $(0 \%)$ had disability, 3(5\%) had mild disability, $45(75 \%)$ participant's moderate disability, $8(13 \%)$ participants had severe disability and $4(7 \%)$ participants had complete disability.

Conclusion: Pain and disability is a prominent features followed by chronic neck pain. The current study developed a foundation for identifying the current state of pain and level of disability among patients with chronic neck pain.

Keywords: neck pain, chronic neck pain, disability
Volume I Issue 2 - 2017

\begin{abstract}
Mohammad HR,' Samena AK, ${ }^{2}$ Ehsanur R,' Shazal KD, ${ }^{2}$ Obaidul $\mathrm{H}^{3}$

'Assistant Professor, Department of Physiotherapy, Bangladesh Health Professions Institute (BHPI), The Academic Institute of Centre for the Rehabilitation of the Paralysed, Bangladesh ${ }^{2}$ Senior Clinical Physiotherapist, Department of Physiotherapy, Centre for the Rehabilitation of the Paralysed Bangladesh ${ }^{3}$ Associate Professor and Head, Department of Physiotherapy, Bangladesh Health Professions Institute (BHPI), The Academic Institute of Centre for the Rehabilitation of the Paralysed, Bangladesh
\end{abstract}

Correspondence: Mohammad Habibur Rahman, Assistant Professor, Department of Physiotherapy, Bangladesh Health Professions Institute (BHPI),The Academic Institute of Centre for the Rehabilitation of the Paralysed (CRP), Chapain, Savar, Dhaka-1343, Bangladesh, Tel +8801919902188, Email sumonpt1983@gmail.com

Received: April 19, 2017 | Published: May 23, 2017

\section{Introduction}

Cervical spine is more vulnerable structure in the body to have mechanical changes due to its anatomical arrangement. ${ }^{1}$ Working posture and degenerative changes within the cervical area causes neck pain. Typically, patient's visiting in Physiotherapy clinic having complaining of neck pain for long period of time and this ultimately leads to develop disability in activities of daily livings. Now a day's neck pain is a major public health problem, ${ }^{2}$ Chronic neck pain is defined as pain in the neck with or without pain referred into one or both upper limbs that lasts for at least 3 months. ${ }^{3}$ Neck pain and other related disorders are very common all over the world. It is the eighth leading cause of disability in the United States and fourth worldwide. ${ }^{4}$ It is also a common symptom among the middle aged population and it has been shown that $24 \%$ of males and $37 \%$ of females suffer from neck pain. ${ }^{2}$ Consequently, neck pain has been a source of disability which may require substantial health care resources and treatments. The growing prevalence of chronic neck pain affects the individuals with different character and ranges of disability. From the best knowledge of the researcher, a healthy number of articles disclaimed the risk factors of work related pattern of neck and its associated factors among different occupational. In order to deliver appropriate interventions, the foundation of category of and disability level is thereby important to discover. Thus, the current study aimed to identify the characteristics of pain and disability among patients with chronic neck pain attending at Centre for the Rehabilitation of the Paralysed (CRP). The researcher believes that this finding of the study would draw the concern of Physiotherapist for future intervention whereby different Physiotherapy treatment techniques would be applied based on not only impairments but also the limitation in activities as well as participation restriction among patients suffering from chronic neck pain.

\section{Methods}

The study design was prospective cross sectional survey. The objectives of the study were to find out the demography of the participants, to find out the medical information, characteristics of pain and disability among patients with chronic neck pain. The study conducted in the outdoor musculoskeletal physiotherapy of Centre for the Rehabilitation of the Paralysed (CRP). Total 60 participants were included in this study based on inclusion criteria such as age range between 20 to 45 years, both genders, participants suffering from neck pain for at least 3 months, diagnosed as nonspecific mechanical neck chronic neck pain and complaining of pain around neck with radiation. Participants were excluded who having age below 20 years and above 45 years, acute or sub-acute neck pain and participants who showed unwillingness to participate. Data were collected through a structured questionnaire consisting of information of participant's demography, characteristics of pain and disability. Pain severity was assessed using $10 \mathrm{~cm}$ numerical pain rating (NPR) scale. The reliability of NPR scale is 0.95 whereas the reliability of VAS is $0.94 .{ }^{6}$ Neck disability was assessed using Neck Disability Index (NDI). The NDI consists of 10 items, each with a score up to 5 , for a total score of 50 . The level of disability is based on cumulative score NDI scale. A score of 0 to 4 refers to no disability, 5 to 14 refer to mild disability, 15-24 refers to moderate disability, 35 or over refers to complete disability. ${ }^{7}$ However, the NDI has demonstrated moderate test re-test reliability 
$(0.68) .{ }^{8}$ Data were evaluated in the form of descriptive statistics using statistical package for social science (SPSS) version 20.

\section{Results}

The mean age (years) of participants was $43.93( \pm 9.75)$ years. Among the 60 participants, $40(67 \%)$ were female and 20(33\%) participants were male. Mean duration of neck pain was 10.85 months, mean $\mathrm{BMI}( \pm \mathrm{SD})$ was $25( \pm 3.61)$. Among 60 participants, $2(3 \%)$ performed static exertion during work, $8(13 \%)$ minimal work, $40(67 \%)$ moderate work and $10(17 \%)$ performed heavy work (Figure 1). However, results were calculated in characteristic of pain and disability level. Majority of the participants $(70 \%)$ had previous episodes of pain and only $30 \%$ participants did not have the previous episodes of pain. In pain section, the behavior of pain was $28(47 \%)$ participants found continuous and $32(53 \%)$ participants reported intermittent pain. The severity of neck pain as per $10 \mathrm{~cm}$ NPR scale showed that 22(37\%) participants were at scale level $3 \mathrm{~cm}, 13(22 \%)$ were at scale level $4 \mathrm{~cm}, 18(30 \%)$ were at scale level $5 \mathrm{~cm}, 3(5 \%)$ were at $6 \mathrm{~cm}, 2(3 \%)$ were at $7 \mathrm{~cm}$ and $2(3 \%)$ were at $8 \mathrm{~cm}$ scale level. In fact, distribution of pain varies among different area of upper limb (Table 1). Time of worse pain among participants was at morning $20(33 \%)$, as the day progress $32(53 \%)$, at night $5(8 \%)$, all day long $3(6 \%)$. In addition with pain, among 60 participants $30(50 \%)$ patients had the complained of paraesthesia, $12(20 \%)$ had tingling sensation and $18(30 \%)$ had numbness. In the disability characteristics among 60 participants, no participants $(0 \%)$ had disability, 3(5\%) had mild disability, $45(75 \%)$ participant's moderate disability, $8(13 \%)$ participants had severe disability and $4(7 \%)$ participants had complete disability (Figure 2).

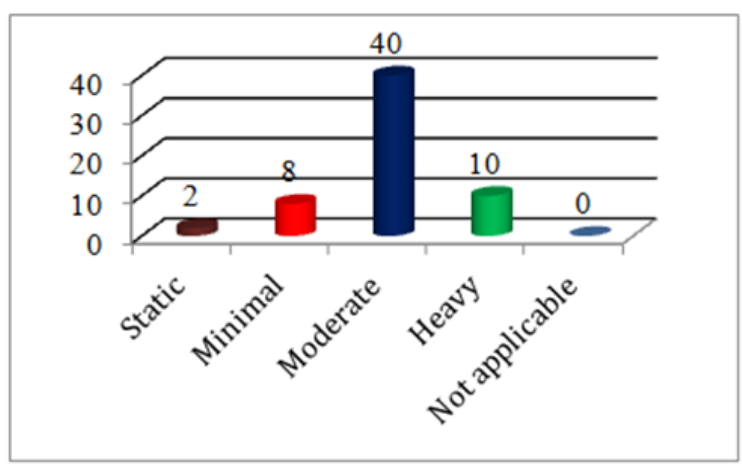

Figure I Exertion during work.

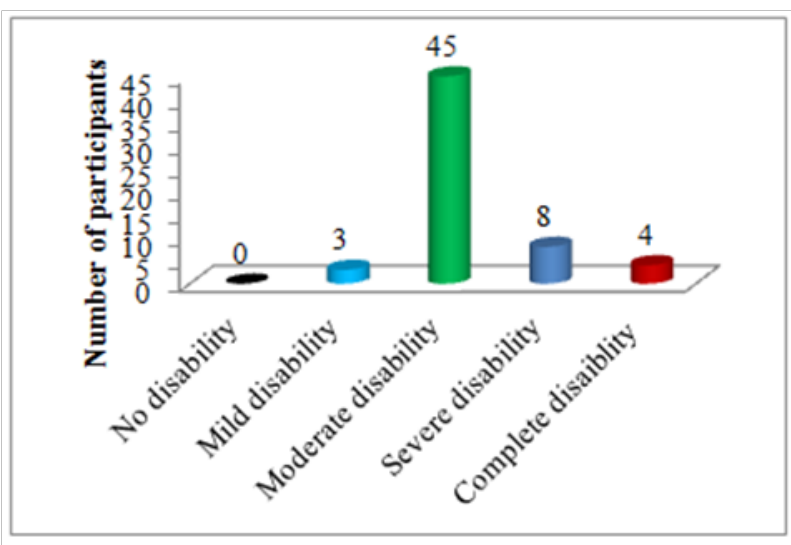

Figure 2 Level of neck disability.
Table I Distribution of pain in neck and upper limb

\begin{tabular}{ll}
\hline Area of pain & Frequency (\%) \\
\hline Neck pain & $18(30)$ \\
Neck pain radiating to right shoulder area & $20(33)$ \\
Neck pain radiating to left shoulder area & $4(7)$ \\
Neck pain radiating to right arm & $6(10)$ \\
Neck pain radiating to left arm & I (2) \\
Neck pain radiating to right forearm & $6(10)$ \\
Neck pain radiating to left forearm & $1(2)$ \\
Neck pain radiating to right fingers & $2(3)$ \\
Neck pain radiating to left fingers & $2(3)$ \\
Total & $60(100)$ \\
\hline
\end{tabular}

\section{Discussion}

The present study found different level of pain and disability status among patients with chronic neck pain. The mean age (years) of participants was $43.93( \pm 9.75)$ years. In contrast, one study reported chronic neck pain patient's mean age $( \pm \mathrm{SD})$ was 20.49 years $( \pm 2.14) .{ }^{9}$ This inequality of age range might have shown different in characteristics of pain. According to this study, highest number of participants (22) showed pain level at $3 \mathrm{~cm}$ in a $10 \mathrm{~cm}$ NPR scale and lowest number of participants (2) had pain level at 7 and $8 \mathrm{~cm}$. In contrast, one study in Canada categorized pain as mild, moderate and severe. In this study, highest number of percentage (54.4\%) of participants complained of moderate pain. ${ }^{10}$ Adding to the nature of pain, the current study found majority of the participants (45) showed moderate disability and least number of participants (3) showed mild disability. Given that another study found highest percentage of participants $(50 \%)$ complained of moderate disability. ${ }^{11}$ Despite the comparing analysis and discussion between current study and previous research, there is few limitation of this study. First, the sample size was small in number and the sampling technique was purposive sampling. For this reason, the study lacks external validity. In other cases, the mean duration of pain was 10.85 months. In view of the researcher, pain and other symptoms following chronic neck pain is a subjective experience and patient might influence the symptoms by hiding the actual status in order to receive concentration from physiotherapist. ${ }^{12}$ Another important point, participants in this study was selected based on non-specific chronic neck pain. However, symptoms of neck pain varies among individual's and moreover among specific disease conditions. As the participants in this study were included based on cervical spondylosis, paraspinal muscle strain, slipped intervertebral disc etc. the severity and nature of symptoms might have varied. ${ }^{13}$

\section{Conclusion}

Chronic neck pain patients showed variety of pain characteristics and level of disability that is crucial to physiotherapist working in musculoskeletal physiotherapy area. Hence, the current study developed a foundation for identifying the current state of pain and level of disability among patients with chronic neck pain.

\section{Clinical Implications}

Characteristics of pain and level of disability varies even in similar disease condition in different patients or different geographic areas. Pain is the presenting symptoms almost every disease process but understanding the characteristics of pain is very much important. In 
addition, chronic pain enforces patients to be disabled in particular works. Thereby, studying the characteristics of pain and disability among patients with chronic neck pain develops a comparative scenario of participants of this study setting and participants of different home and abroad study settings. Conversely, Physiotherapists working in the musculoskeletal unit of CRP could have an idea about pain and it's characteristic and corresponding level of disability which in turn help them in considering those factors during treatment goal setting and implementation of treatment technique.

\section{Acknowledgements}

None

\section{Conflict of interest}

The author declares no conflict of interest

\section{References}

1. Boyles R, Toy P, Mellon J, et al. Effectiveness of manual physical therapy in the treatment of cervical radiculopathy: a systematic review. $J$ Man Manip. 2011;19(3):135-142.

2. Mantyselka P, Kautiainen H, Vanhala M. Prevalence of neck pain in subjects with metabolic syndrome - a cross-sectional population-based study. BMC Musculoskeletal disorders. 2010;11(171):1471-2474.

3. Hoy D, March L, Woolf A, et al. The global burden of neck pain: estimates from the Global Burden of Disease 2010 study. Ann Rheum Dis. 2014;73(7):1309-1315.

4. Sberman KJ, Cook AJ, Wellman RD, et al. Five- week outcomes from a dosing trial of therapeutic massage for chronic neck pain. Ann Fam Med. 2014;12(2):112-120.
5. Cheng YH, Huang GC. Efficacy of massage therapy on pain and dysfunction in patients with neck pain : A systematic review and metaanalysis. Evidence-Based Complementary and Alternative Medicine. 2014;(1):1-13

6. Hawker GA, Mian S, Kendzerska T, et al. Measures of Adult Pain. Arthritis Care Res (Hoboken). 2011;63(11):240-252.

7. Vernon H. The Neck Disability Index: State-of-the-art, 1991-2008. J Manipulative Physiol Ther. 2008;31(7):491-502.

8. Jun I, Kim K. A Comparison of the Deep Cervical Flexor Muscle Thicknesses in Subjects with and without Neck Pain during Craniocervical Flexion Exercises. J Phys Ther Sci. 2013;25(11):1373-1375.

9. Gharib NMM, Hamid NS. Prevalence of mechanical neck pain in Taif university female students: a survey study. Journal of American Science. 2013;9(6):347-352.

10. Schopflocher D, Taenzer P, Jovey R. The Prevalence of chronic pain in Canada. Pain Res Manag. 2011;16(6):445-450.

11. Jeyanthi S, Arumugam N. Effectiveness of Cranio-cervical Training over Myofascial Pain Syndrome: A Case Study. Int J Physiother Res. 2015;3(3):1032-1036.

12. Wilde VE, Ford JJ, Mcmeeken JM. Indicators of lumber zygopophysial joint pain: survey of an expert panel with the Delphi Technique. Journal of the American Physical Therapy Association. 2007;87(10):1348-1361.

13. Misailidou V, Malliou P, Beneka A, et al. Assessment of patients with neck pain: a review of definitions, selection criteria, and measurement tools. Journal of Chiropractic Medicine. 2010;9(2):49-59. 